\title{
Prevalence of multidrug-resistant Helicobacter pylori in Bulgaria
}

\author{
Lyudmila Boyanova
}

Correspondence

Lyudmila Boyanova

I.boyanova@hotmail.com

Received 3 February 2009

Accepted 13 March 2009
Chair of Microbiology, Medical University of Sofia, Sofia, Bulgaria

\begin{abstract}
The aim of this study was to evaluate the presence and prevalence of multidrug antibacterial resistance in Helicobacter pylori in Bulgaria from 2005 to 2008. The resistance in 828 untreated adults, 124 treated adults and 105 untreated children was, respectively, 26.5, 50.8 and $16.2 \%$ for metronidazole; 18.4, 45.2 and $19 \%$ for clarithromycin; $1,2.4$ and $0 \%$ for amoxicillin; 4.4, 10.6 and $1.9 \%$ for tetracycline; and $9,14.5$ and $5.8 \%$ for ciprofloxacin. Triple resistance to the evaluated agents was uncommon and was detected in $1 \%$ of the untreated children, $3.5 \%$ of the untreated adults and $13.6 \%$ of the treated adults. Five $H$. pylori strains were resistant to amoxicillin, metronidazole and clarithromycin, two of them exhibiting quadruple resistance. Resistance to four of the five antibacterials tested was found in $0.7 \%$ of the untreated and $1.8 \%$ of the treated adults. The overall level of multidrug resistance in the treated adults $(15.4 \%)$ was higher than that in the untreated adults $(4.2 \%, P=0.0001)$ and the untreated children $(1 \%$, $P=0.0001)$. The presence of multidrug $H$. pylori resistance in Bulgaria could be associated with many factors, among them the slightly increasing national use of macrolides, lincosamides and streptogramins and of quinolones since 2000 , the significant increase in primary $H$. pylori clarithromycin resistance, the high tetracycline use between 1994 and 1999, and, in individual cases, the use of azithromycin-based regimens or reuse of nitroimidazoles. In conclusion, for the first time in a European country during the last 5 years, $H$. pylori strains harbouring a worrying quadruple antibacterial resistance were found in treated as well as in untreated patients. $H$. pylori susceptibility patterns have a tendency to become unpredictable and should be monitored constantly at both national and global levels.
\end{abstract}

\section{INTRODUCTION}

One important reason for the failure of Helicobacter pylori eradication is antibacterial resistance (Morgner et al., 2006). This resistance is most often due to point mutations and can result from inappropriate or frequent antibiotic use (Megraud \& Lehours, 2007). The genes responsible for the mutations are the 23S rRNA gene for the macrolides, $r d x A$ and $f r x A$ for metronidazole, $g y r A$ for the quinolones, $r p o B$ for rifampin, $p b p 1$ for amoxicillin and the 16S rRNA gene for tetracycline (Megraud \& Lehours, 2007). In addition, some non-specific proteins, such as HP1092 and the hefC gene product, have been associated with $H$. pylori multidrug resistance (Kutschke \& de Jonge, 2005; Saidijam et al., 2006).

In adults, the primary $H$. pylori resistance rates to clarithromycin vary from 0 to $25 \%$ (Megraud \& Lehours, 2007). Macrolide resistance is sometimes higher in children than in adults because children are treated

Abbreviations: BST, breakpoint susceptibility testing; DID, defined daily doses per 1000 inhabitants per day; GORD, gastro-oesophageal reflux disease; PPI, proton pump inhibitor. with macrolides for respiratory infections more often than adults (Koletzko et al., 2006). Primary resistance rates to metronidazole have been $20-40 \%$ in the USA and Europe, but in developing countries, the rates have been higher (from 50 to $>80 \%$ ), whilst conversely, in Japan, the rates have been low (1.1-12\%) (Kobayashi et al., 2007; Megraud \& Lehours, 2007). Primary H. pylori resistance to amoxicillin is uncommon (often $0-2 \%$ ) and has been detected in only a few countries; similarly, tetracycline resistance is low except for several countries such as South Korea and Taiwan (Hu et al., 2007). Conversely, because of the increasing use of fluoroquinolones in many countries, quinolone resistance in $H$. pylori has increased and has reached $>20 \%$ in adult patients in Japan and Portugal (Megraud \& Lehours, 2007; Miyachi et al., 2006). Post-treatment resistance to gatifloxacin has been found to be $47.9 \%$ in Japan (Nishizawa et al., 2006). The double-drug H. pylori resistance rate has usually been $<10 \%$ in Europe (Koletzko et al., 2006; Megraud \& Lehours, 2007), whilst triple resistance to amoxicillin, metronidazole and clarithromycin in $H$. pylori has been only occasional (Torres et al., 2001). 
The aim of the present study was to evaluate the presence and prevalence of multidrug-resistant $H$. pylori in Bulgaria between 2005 and 2008.

\section{METHODS}

Patients and specimens. A total of 1057 consecutive $H$. pylori strains, isolated in 2005-2008, were evaluated, comprising strains from untreated adults aged 18-87 years (mean age 43.5 years, 828 cases), untreated children aged 3-17 years (mean age 12.0 years, 105 cases) and treated adults aged 18-75 years (mean age 46.5 years, 124 cases). The untreated children comprised 46 boys and 59 girls, the untreated adults 471 men and 357 women, and the treated adults 72 men and 52 women. The untreated children had chronic gastritis ( 86 cases), duodenal ulcer (nine cases), gastric ulcer (one case), gastrooesophageal reflux disease (GORD; five cases) and other diseases (four cases). The untreated and treated adults had chronic gastritis (428 and 60 cases, respectively), duodenal ulcer (200 and 28 cases), gastric ulcer (58 and 12 cases), gastric cancer (six and one cases), GORD (125 and 16 cases) and other diseases, such as gastric polyp and hiatal hernia (11 and seven cases). Informed written consent was obtained from all adults and the parents of all children. The isolation and identification of strains were performed as described previously (Boyanova et al., 2008). Specimens from the treated patients were taken at least 1 month after the end of the $H$. pylori treatment. The most common eradication regimens involved: (i) a proton pump inhibitor (PPI; omeprazole or esomeprazole) + amoxicillin + clarithromycin (38 cases); (ii) PPI + amoxicillin + metronidazole (22 cases); (iii) PPI + amoxicillin + azithromycin (three cases); (iv) $\mathrm{PPI}+$ clarithromycin + metronidazole (one case); (v) metronidazole + tetracycline + bismuth compounds + PPI (four cases); (vi) PPI + amoxicillin + clarithromycin + bismuth compounds (one case); and (vii) more than one regimen (five cases). No data were available for the previous treatment of the remaining 50 patients.

Microbiology. The breakpoint susceptibility testing (BST) method is a simplified agar dilution method, using one to four consecutive concentrations of the antibacterial agent. In our previous study, the category agreement between the BST and the Etest or agar dilution method results was found to be high (93.3-100\%) (Boyanova et al., 2008). In the present study, BST was used for susceptibility testing of H. pylori as described previously (Boyanova et al., 2008). Briefly, $H$. pylori suspensions were inoculated onto Mueller-Hinton blood agar plates (National Centre of Infectious and Parasitic Diseases, Sofia, Bulgaria) containing one of the following drug concentrations: 8, 16 and $32 \mu \mathrm{g}$ metronidazole $\mathrm{ml}^{-1} ; 0.25,0.5,1$ and $2 \mu \mathrm{g}$ clarithromycin $\mathrm{ml}^{-1} ; 0.5,1$ and $2 \mu \mathrm{g}$ amoxicillin $\mathrm{ml}^{-1} ; 4 \mu \mathrm{g}$ tetracycline $\mathrm{ml}^{-1}$; and $1 \mu \mathrm{g}$ ciprofloxacin $\mathrm{ml}^{-1}$. Susceptibility testing for ciprofloxacin was carried out as a marker for strain susceptibility to newer quinolones such as levofloxacin (Megraud \& Lehours, 2007). The plates were incubated microaerophilically (Campy Pak; BBL) at $35^{\circ} \mathrm{C}$ for $2-$ 3 days. Non-selective Mueller-Hinton blood agar plates were used as a control of strain viability.

The susceptibility patterns of 15 strains with multidrug resistance (eight randomly selected strains with triple resistance and all seven strains with quadruple resistance) were also evaluated by the agar dilution method for metronidazole and Etest (AB Biodisk and Oxoid) for the other agents. Bacterial suspensions (density of 2-3 McFarland standards) were prepared in Mueller-Hinton broth and inoculated onto Mueller-Hinton agar with $5 \%$ sheep blood. Etest strips were placed on the plates (one strip per $90 \mathrm{~mm}$ diameter plate) and the plates were incubated at $35^{\circ} \mathrm{C}$ for $48-72 \mathrm{~h}$ in microaerophilic conditions (as above). The results were read according to the supplier's recommendations.
The breakpoints for resistance were $>8 \mu \mathrm{g}$ metronidazole $\mathrm{ml}^{-1}$, $\geqslant 1 \mu \mathrm{g}$ clarithromycin $\mathrm{ml}^{-1},>0.5 \mu \mathrm{g}$ amoxicillin $\mathrm{ml}^{-1},>4 \mu \mathrm{g}$ tetracycline $\mathrm{ml}^{-1}$ and $>1 \mu \mathrm{g}$ ciprofloxacin $\mathrm{ml}^{-1}$ (Megraud et al., 1999; NCCLS, 2000; Megraud \& Lehours, 2007, Glocker et al., 2007). Secondary resistance was defined as resistance acquired during treatment by a strain that was susceptible to the agent before treatment. The control strains used for the BST and agar dilution method were two laboratory H. pylori isolates with known MICs, as well as Staphylococcus aureus ATCC 29213, Escherichia coli ATCC 25922, Pseudomonas aeruginosa ATCC 27853 and Bacteroides fragilis ATCC 25285 (with an appropriate anaerobic incubation).

Statistical analysis. Differences between the groups were assessed with a $\chi^{2}$ test or Fisher's exact test, as appropriate. $P$ values $<0.05$ were considered significant.

\section{RESULTS AND DISCUSSION}

In the present study, $H$. pylori resistance rates in untreated adults and children were found to be: metronidazole $26.5 \%(218 / 822$ patients $)$ and $16.2 \%(17 / 105)$, respectively; clarithromycin $18.4 \%(152 / 828)$ and $19.0 \%(20 /$ $105)$; amoxicillin $1.0 \%(8 / 825)$ and $0.0 \%(0 / 105)$; tetracycline $4.4 \%(33 / 744)$ and $1.9 \%$ (2/103); ciprofloxacin $9.0 \%(71 / 787)$ and $5.8 \%(6 / 103)$; metronidazole + clarithromycin $8.0 \%(66 / 822)$ and $6.7 \%(7 / 105)$; and amoxicillin + metronidazole + clarithromycin $0.2 \%(2 / 822)$ and $0 \%(0 / 105)$. Primary resistance to metronidazole was significantly more common in untreated adults $(26.5 \%$, $218 / 822$ patients) than in untreated children $(16.2 \%, 17 /$ $105, P=0.022)$, whereas the differences in the resistance rates to the other agents were not significant $(P \geqslant 0.278)$.

The primary resistance rates of $H$. pylori were in the range of those frequently reported in Europe with slightly higher amoxicillin and tetracycline resistance rates and a lower metronidazole resistance rate in children. The primary resistance rate to clarithromycin was similar to that found in eastern and southern Europe (usually about 18\%) (Megraud \& Lehours, 2007).

The reported resistance of $H$. pylori in treated children and adults (35-68\% to metronidazole, $17-63 \%$ to clarithromycin and $15-73 \%$ to metronidazole + clarithromycin) can hinder the success of eradication (Chisholm et al., 2007; Gosciniak et al., 2004; Kalach et al., 2007; Koletzko et al., 2006; Toracchio \& Marzio, 2003; Tüzün et al., 2008). With the increasing number of prescriptions for $H$. pylori eradication and the involvement of new treatment regimens, post-treatment resistance to amoxicillin, tetracycline and quinolones has also been reported (Hsu et al., 2008; Koletzko et al., 2006; Nishizawa et al., 2006). Hsu et al. (2008) detected H. pylori resistance to amoxicillin and levofloxacin in 17 and $22 \%$ of patients, respectively, after treatment with rabeprazole, bismuth compounds, amoxicillin and levofloxacin.

In the present study, $H$. pylori resistance rates in treated adults were: metronidazole $50.8 \%$ (63/124 patients), clarithromycin $45.2 \%(56 / 124)$, amoxicillin $2.4 \%$ (3/ $124)$, tetracycline $10.6 \%(13 / 123)$, ciprofloxacin $14.5 \%$ 
(16/110), metronidazole + clarithromycin $28.2 \%(35 / 124)$ and amoxicillin + metronidazole + clarithromycin $2.4 \%$ $(3 / 124)$. The rates of secondary resistance to metronidazole $(88.8 \%, 8 / 9$ strains) and clarithromycin $(57.1 \%, 4 / 7)$ were high, unlike those to amoxicillin $(0 \%, 0 / 16)$.

Multidrug resistance of $H$. pylori is occasional and found in individual countries or regions, for example in Sardinia, Mexico and Taiwan (Hu et al., 2007; Kwon et al., 2003). Resistance to amoxicillin, metronidazole and clarithromycin was detected in $6.8 \%$ of 44 Chinese children (Chen et al., 2004 ), as well as in $4 \%$ of the evaluated children and in $10.4 \%$ of the evaluated adults in Mexico (Torres et al., 2001). In the present study, five $(0.5 \%) \mathrm{H}$. pylori strains of the 1051 strains tested for susceptibility to amoxicillin, metronidazole and clarithromycin were resistant to these three agents, with two of the strains exhibiting quadruple resistance.

Within the strains tested for susceptibility to all five antibacterial agents, the total multidrug resistance rate in treated adults $(15.4 \%, 17 / 110$ patients) was higher than that in untreated adults $(4.2 \%, 31 / 744, P=0.0001)$ and untreated children $(1 \%, 1 / 103, P=0.0001)$. The triple and quadruple resistance rates were $1 \%(1 / 103$ patients) and $0 \%(0 / 103)$ for the untreated children, $3.5 \%(26 / 744)$ and $0.7 \%(5 / 744)$ for the untreated adults, and $13.6 \%(15 / 110)$ and $1.8 \%(2 / 110)$, respectively, for the treated adults. It is of note that triple resistance to metronidazole, clarithromycin and tetracycline was found in an untreated 13-year-old girl with chronic gastritis.

It is known that the success of eradication of clarithromycin-resistant strains is $40-70 \%$ lower than that of susceptible strains (Megraud, 2004; Peitz et al., 2002). Metronidazole resistance is less important, usually decreasing the success of eradication by $25 \%$ (Bazzoli et al., 1999; Megraud \& Lehours, 2007; Peitz et al., 2002). Amoxicillin resistance of $H$. pylori could also be clinically important. Although Kim et al. (2006) reported that amoxicillin resistance in $H$. pylori did not influence the success of eradication, other authors (Domingo et al., 2002) have detected decreased eradication success of strains with MICs $\geqslant 0.032 \mu \mathrm{g}$ amoxicillin $\mathrm{ml}^{-1}$.

At present, the best-validated first-line regimen for $H$. pylori eradication consists of a PPI + clarithromycin + amoxicillin administered for 7-14 days (Malfertheiner et al., 2007). Within the strains tested for susceptibility to all five antibacterial agents in the present study, no significant differences were found between the resistance rate to both amoxicillin and clarithromycin $(0 \%, 0 / 103$ patients) in the untreated children and those in the untreated $(0.3 \%, 2 / 744$, $P=1.000)$ and treated adults $(3.6 \%, 4 / 110, P=0.122)$.

Quadruple resistance of $H$. pylori has not been reported in Europe and the USA during the last 5 years, although a study from India has reported this type of resistance in $2.6 \%$ of isolates (Thyagarajan et al., 2003). Within the strains tested for susceptibility to all five antibacterial agents in the present study, quadruple $H$. pylori resistance was detected in $0.7 \%$ (5/744 patients) of the untreated and in $1.8 \%(2 / 110)$ of the treated adults (Table 1). This quadruple resistance was found in six men and one woman. These patients had chronic gastritis (three cases), duodenal ulcer (three cases) and GORD (one case), and five cases were untreated and two were treated (Table 2).

Table 1. Multidrug resistance in H. pylori between 2005 and 2008

\begin{tabular}{|c|c|c|c|c|c|c|c|c|c|}
\hline \multirow[t]{2}{*}{ Agents } & \multicolumn{3}{|c|}{ Untreated children } & \multicolumn{3}{|c|}{ Untreated adults } & \multicolumn{3}{|c|}{ Treated adults } \\
\hline & $\begin{array}{l}\text { No. of } \\
\text { strains }\end{array}$ & $\begin{array}{l}\text { No. } \\
\text { resistant }^{*}\end{array}$ & $\begin{array}{c}\% \\
\text { Resistant }\end{array}$ & $\begin{array}{l}\text { No. of } \\
\text { strains }\end{array}$ & $\begin{array}{l}\text { No. } \\
\text { resistant }\end{array}$ & $\begin{array}{c}\% \\
\text { Resistant }\end{array}$ & $\begin{array}{l}\text { No. of } \\
\text { strains }\end{array}$ & $\begin{array}{l}\text { No. } \\
\text { resistant }\end{array}$ & $\begin{array}{c}\% \\
\text { Resistant }\end{array}$ \\
\hline $\begin{array}{l}\text { Metronidazole }+ \text { clarithromycin }+ \\
\text { ciprofloxacin }\end{array}$ & 103 & 0 & 0 & 787 & 13 & 1.6 & 110 & 4 & 3.6 \\
\hline $\begin{array}{l}\text { Metronidazole }+ \text { clarithromycin }+ \\
\text { tetracycline }\end{array}$ & 103 & 1 & 1.0 & 744 & 5 & 0.7 & 123 & 6 & 4.9 \\
\hline $\begin{array}{l}\text { Metronidazole }+ \text { tetracycline }+ \\
\text { ciprofloxacin }\end{array}$ & 103 & 0 & 0 & 744 & 5 & 0.7 & 110 & 3 & 2.7 \\
\hline $\begin{array}{l}\text { Amoxicillin }+ \text { metronidazole }+ \\
\text { clarithromycin }\end{array}$ & 105 & 0 & 0 & 822 & 1 & 0.1 & 124 & 2 & 1.6 \\
\hline Amoxicillin + metronidazole + ciprofloxacin & 103 & 0 & 0 & 787 & 1 & 0.1 & 110 & 0 & 0 \\
\hline Clarithromycin + tetracycline + ciprofloxacin & 103 & 0 & 0 & 744 & 1 & 0.1 & 110 & 0 & 0 \\
\hline $\begin{array}{l}\text { Metronidazole + clarithromycin }+ \\
\text { tetracycline }+ \text { ciprofloxacin }\end{array}$ & 103 & 0 & 0 & 744 & 4 & 0.5 & 110 & 1 & 0.9 \\
\hline $\begin{array}{l}\text { Amoxicillin }+ \text { metronidazole }+ \\
\text { clarithromycin }+ \text { tetracycline }\end{array}$ & 103 & 0 & 0 & 744 & 1 & 0.1 & 123 & 0 & 0 \\
\hline $\begin{array}{l}\text { Amoxicillin }+ \text { metronidazole }+ \\
\text { clarithromycin }+ \text { ciprofloxacin }\end{array}$ & 103 & 0 & 0 & 787 & 0 & 0 & 110 & 1 & 0.9 \\
\hline Total multidrug resistance ${ }^{\star}$ & 103 & 1 & 1.0 & 744 & 31 & 4.2 & 110 & 17 & 15.4 \\
\hline
\end{tabular}

*Within the strains tested for susceptibility to all five antibacterial agents. 
Table 2. Characteristics of the seven patients with quadruple resistance, with previous resistance patterns for the treated patients M, Male; F, female; R, resistant; S, sensitive.

\begin{tabular}{|c|c|c|c|c|c|c|c|c|c|}
\hline \multirow[t]{2}{*}{ No. } & \multirow[t]{2}{*}{ Sex } & \multirow[t]{2}{*}{ Age (years) } & \multirow[t]{2}{*}{ Disease } & \multirow[t]{2}{*}{ Treatment } & \multicolumn{5}{|c|}{$\mathrm{R} / \mathrm{S}\left(\mathrm{MIC} ; \mu \mathrm{g} \mathrm{ml}^{-1}\right)$} \\
\hline & & & & & Amoxicillin & Metronidazole & Clarithromycin & Tetracycline & Ciprofloxacin \\
\hline 2 & M & 46 & Chronic gastritis & Untreated & $S(0.125)$ & $\mathrm{R}(>32)$ & $\mathrm{R}(256)$ & $\mathrm{R}(64)$ & $\mathrm{R}(>32)$ \\
\hline 3 & M & 28 & Chronic gastritis & Untreated & $S(\leqslant 0.125)$ & $\mathrm{R}(>32)$ & $\mathrm{R}(6)$ & $\mathrm{R}(64)$ & $\mathrm{R}(4)$ \\
\hline 4 & M & 53 & Chronic gastritis & Untreated & $S(\leqslant 0.125)$ & $\mathrm{R}(>32)$ & $\mathrm{R}(256)$ & $\mathrm{R}(8)$ & $\mathrm{R}(2)$ \\
\hline 6 & & & & Treated $\S$ & $S(\leqslant 0.125)$ & $\mathrm{R}(>32)$ & $\mathrm{R}(6)$ & $\mathrm{R}(128)$ & $\mathrm{R}(>32)$ \\
\hline \multirow[t]{2}{*}{7} & M & 42 & GORD & Untreated & $\mathrm{R}(1)$ & $\mathrm{R}(>32)$ & S (0.19) & $S(\leqslant 0.125)$ & $\mathrm{R}(>32)$ \\
\hline & & & & TreatedII & $\mathrm{R}(1)$ & $\mathrm{R}(>32)$ & $\mathrm{R}(\geqslant 256)$ & $S(\leqslant 0.125)$ & $\mathrm{R}(>32)$ \\
\hline
\end{tabular}

*Treated with omeprazole, amoxicillin and metronidazole.

$\ddagger$ Resistant subpopulation.

§Treated with omeprazole, amoxicillin, tinidazole, tetracycline and bismuth compound.

IINo data about the treatment regimen.

The prevalence of $H$. pylori strains with multidrug antibiotic resistances did not increase during the study period. Within the strains tested for susceptibility to all five antibacterial agents, the frequencies of $H$. pylori strains with multidrug antibiotic resistances in 2005-2006 and in 2007-2008 were 2.0 ( $1 / 50$ cases) and $0.0 \%(0 / 53, P=0.485)$ for the untreated children, $3.7(16 / 436)$ and $5.2 \%(16 / 308$, $P=0.312)$ for the untreated adults, and $19.6(11 / 56)$ and $11.1 \%(6 / 54, P=0.216)$ for the treated adults.

Except for amoxicillin, the $\mathrm{MIC}_{90}$ values of the antibacterial agents against all strains with multidrug resistance were very high $\left(>32 \mu \mathrm{g} \mathrm{ml}^{-1}\right.$ ) (Table 3$)$. The MICs for the strains with quadruple resistance to clarithromycin $\left(\mathrm{MIC}_{50}\right.$ $256 \mu \mathrm{g} \mathrm{ml}^{-1}$ and $\mathrm{MIC}_{90}>256 \mu \mathrm{g} \mathrm{ml}^{-1}$ ) and tetracycline $\left(\mathrm{MIC}_{50}>32 \mu \mathrm{g} \mathrm{ml}^{-1}\right.$ ) were higher than those for strains with triple resistance $\left(\mathrm{MIC}_{50} 3 \mu \mathrm{g} \mathrm{ml}^{-1}\right.$, MIC $9064 \mu \mathrm{g} \mathrm{ml}^{-1}$ for clarithromycin and $\mathrm{MIC}_{50} 0.5 \mu \mathrm{g} \mathrm{ml}^{-1}$ for tetracycline).

H. pylori strains harbouring triple or quadruple resistance could hinder the choice and success of the eradication regimen. According to one study, treatment using triple combinations containing amoxicillin was unsuccessful in a

Table 3. MICs $\left(\mu \mathrm{g} \mathrm{ml}^{-1}\right)$ of antibacterial agents against 15 multidrug-resistant $H$. pylori isolates by the agar dilution method (ADM) for metronidazole and Etest for the other agents

\begin{tabular}{|lcrl|}
\hline Agent (method) & MIC $_{\mathbf{5 0}}$ & MIC $_{\mathbf{9 0}}$ & Range \\
\hline Clarithromycin (Etest) & 6 & $>256$ & 0.023 to $>256$ \\
Metronidazole (ADM) & $>32$ & $>32$ & 0.25 to $>32$ \\
Amoxicillin (Etest) & $\leqslant 0.125$ & 1 & $\leqslant 0.125$ to 1 \\
Tetracycline (Etest) & 8 & $>32$ & $\leqslant 0.125$ to $>32$ \\
Ciprofloxacin (Etest) & 4 & $>32$ & $\leqslant 0.125$ to $>32$ \\
\hline
\end{tabular}

patient with $H$. pylori resistance to amoxicillin, clarithromycin and metronidazole (Han et al., 1999). In Korea, $89.6 \%$ of patients with eradication failure have been found to harbour $H$. pylori strains resistant to two or more antimicrobial agents (Kim, 2006).

Of the 48 strains with multidrug resistance to metronidazole and other agents, eight (16.7\%) had MICs of $16 \mu \mathrm{g}$ metronidazole $\mathrm{ml}^{-1}$. For similar strains, a quadruple therapy with lansoprazole, bismuth subsalicylate, metronidazole (reuse) and tetracycline for 14 days was found to be effective in $>70 \%$ of patients (Magaret et al., 2001). Several empirical 'rescue' therapy regimens have been recommended for $H$. pylori eradication after failure of two eradication treatments, for example amoxicillin/PPI at high doses, rifabutin/amoxicillin/PPI or furazolidone/bismuth/ tetracycline/PPI (Gisbert \& Pajares, 2005). Adding nonantimicrobial agents (e.g. lactobacilli) to the eradication regimens can be beneficial to increase the eradication rate by up to $10 \%$ or to minimize the side effects (LesbrosPantoflickova et al., 2007). It is important to retreat unsuccessfully treated patients using a case-by-case approach and to perform a susceptibility-guided retreatment if available (Di Mario et al., 2006).

Within the treated patients with a known previous eradication regimen, multidrug resistance was detected after treatment with PPI + amoxicillin + metronidazole (3/ 22 cases), PPI + amoxicillin + clarithromycin (2/38), PPI + amoxicillin + azithromycin (1/3), PPI + metronidazole + tetracycline + bismuth compounds(1/4), and in more than one regimen (1/5). The presence of multidrug resistance in $H$. pylori in Bulgaria could be associated with the slightly increasing national use of macrolides, lincosamides and streptogramins [J01F, 1.75 defined daily doses per 1000 inhabitants per day (DID) in 2006] and 
quinolones (J01M, 1.79 DID in 2006) since 2000 (European Surveillance of Antimicrobial Consumption data for 2006; http://www.esac.ua.ac.be/). Although its use has been decreasing since 2000 (to 2.42 DID in 2006), tetracycline use was very high $(>4.2$ DID) from 1994 to 1999 (Markova et al., 2005). Within the European countries in 2006, Bulgaria has been a country of moderate total antibiotic use (Muller et al., 2007). However, it is of note that, in Bulgaria, primary clarithromycin resistance in H. pylori has increased significantly from $10 \%$ in 19961999 to $17.9 \%$ in 2005-2007 (Boyanova et al., 2008). Overall primary metronidazole resistance was stable during this period. Other reasons for unsuccessful eradication and the appearance of multidrug resistance could be the use of azithromycin-based triple regimens in three cases, including one case with triple resistance of the strain, and the reuse of nitroimidazoles in one case. Anagnostopoulos et al. (2003) reported successful eradication after azithromycin-based triple regimens in only $62-71 \%$ of the evaluated patients.

In conclusion, multidrug (triple and quadruple) resistance to the key antibacterial agents for eradication of $H$. pylori infection was generally uncommon but was present in $1 \%$ (1/103 cases) of untreated children, in $4.2 \%(31 / 744)$ of untreated adults and in a higher proportion $(15.4 \%, 17 /$ 110) of treated adults. Eradication of $H$. pylori strains harbouring multidrug resistance requires susceptibility testing of the isolate and should be determined with caution for individual patients. H. pylori susceptibility patterns tend to become unpredictable and should be monitored constantly at both national and global levels.

\section{REFERENCES}

Anagnostopoulos, G. K., Kostopoulos, P., Margantinis, G., Tsiakos, S. \& Arvanitidis, D. (2003). Omeprazole plus azithromycin and either amoxicillin or tinidazole for eradication of Helicobacter pylori infection. J Clin Gastroenterol 36, 325-328.

Bazzoli, F., Berretti, D., De Luca, L., Nicolini, G., Pozzato, P., Fossi, S. \& Zagari, M. (1999). What can be learnt from the new data about antibiotic resistance? Are there any practical clinical consequences of Helicobacter pylori antibiotic resistance? Eur J Gastroenterol Hepatol 11 (Suppl. 2), S39-S42.

Boyanova, L., Gergova, G., Nikolov, R., Davidkov, L., Kamburov, V., Jelev, C. \& Mitov, I. (2008). Prevalence and evolution of Helicobacter pylori resistance to 6 antibacterial agents over 12 years and correlation between susceptibility testing methods. Diagn Microbiol Infect Dis 60, 409-415.

Chen, J., Chen, F. B., Yu, J. D., Chen, X. J., Li, Z. Y. \& Zhang, X. P. (2004). Prevalence of Helicobacter pylori resistant to clarithromycin, amoxicillin and metronidazole in children. Zhonghua $\mathrm{Er} \mathrm{Ke} \mathrm{Za} \mathrm{Zhi} \mathrm{42,}$ 769-771.

Chisholm, S. A., Teare, E. L., Davies, K. \& Owen, R. J. (2007). Surveillance of primary antibiotic resistance of Helicobacter pylori at centres in England and Wales over a six-year period (2000-2005). Euro Surveill 12, E3-E4.

Di Mario, F., Cavallaro, L. G. \& Scarpignato, C. (2006). 'Rescue' therapies for the management of Helicobacter pylori infection. Dig Dis 24, 113-130.
Domingo, D., Alarcón, T., Vega, A. E., García, J. A., Martínez, M. J. \& López-Brea, M. (2002). Microbiological factors that influence the eradication of Helicobacter pylori in adults and children. Enferm Infecc Microbiol Clin 20, 431-434.

Gisbert, J. P. \& Pajares, J. M. (2005). Helicobacter pylori "rescue" therapy after failure of two eradication treatments. Helicobacter 10, 363-372.

Glocker, E., Stueger, H. P. \& Kist, M. (2007). Quinolone resistance in Helicobacter pylori isolates in Germany. Antimicrob Agents Chemother 51, 346-349.

Gosciniak, G., Iwanczak, B., Przondo-Mordarska, A., Grabinska, J. \& Iwanczak, F. (2004). High level of resistance to metronidazole and clarithromycin in Helicobacter pylori isolated from pediatric patients in Poland (1997-2001). Folia Microbiol (Praha) 49, 133-136.

Han, S. R., Bhakdi, S., Maeurer, M. J., Schneider, T. \& Gehring, S. (1999). Stable and unstable amoxicillin resistance in Helicobacter pylori: should antibiotic resistance testing be performed prior to eradication therapy? J Clin Microbiol 37, 2740-2741.

Hsu, P. I., Wu, D. C., Chen, A., Peng, N. J., Tseng, H. H., Tsay, F. W., Lo, G. H., Lu, C. Y., Yu, F. J. \& Lai, K. H. (2008). Quadruple rescue therapy for Helicobacter pylori infection after two treatment failures. Eur J Clin Invest 38, 404-409.

Hu, C. T., Wu, C. C., Lin, C. Y., Cheng, C. C., Su, S. C., Tseng, Y. H. \& Lin, N. T. (2007). Resistance rate to antibiotics of Helicobacter pylori isolates in eastern Taiwan. J Gastroenterol Hepatol 22, 720-723.

Kalach, N., Serhal, L., Asmar, E., Campeotto, F., Bergeret, M., Dehecq, E., Spyckerelle, C., Charkaluk, M. L., Decoster, A. \& other authors (2007). Helicobacter pylori primary resistant strains over 11 years in French children. Diagn Microbiol Infect Dis 59, 217-222.

Kim, J. M. (2006). Antibiotic resistance of Helicobacter pylori isolated from Korean patients. Korean J Gastroenterol 47, 337-349.

Kim, N., Kim, J. M., Kim, C. H., Park, Y. S., Lee, D. H., Kim, J. S., Jung, H. C. \& Song, I. S. (2006). Institutional difference of antibiotic resistance of Helicobacter pylori strains in Korea. J Clin Gastroenterol 40, 683-687.

Kobayashi, I., Murakami, K., Kato, M., Kato, S., Azuma, T., Takahashi, S., Uemura, N., Katsuyama, T., Fukuda, Y. \& other authors (2007). Changing antimicrobial susceptibility epidemiology of Helicobacter pylori strains in Japan between 2002 and 2005. J Clin Microbiol 45, 4006-4010.

Koletzko, S., Richy, F., Bontems, P., Crone, J., Kalach, N., Monteiro, M. L., Gottrand, F., Celinska-Cedro, D., Roma-Giannikou, E. \& other authors (2006). Prospective multicentre study on antibiotic resistance of Helicobacter pylori strains obtained from children living in Europe. Gut 55, 1711-1716.

Kutschke, A. \& de Jonge, B. L. (2005). Compound efflux in Helicobacter pylori. Antimicrob Agents Chemother 49, 3009-3010.

Kwon, D. H., Dore, M. P., Kim, J. J., Kato, M., Lee, M., Wu, J. Y. \& Graham, D. Y. (2003). High-level $\beta$-lactam resistance associated with acquired multidrug resistance in Helicobacter pylori. Antimicrob Agents Chemother 47, 2169-2178.

Lesbros-Pantoflickova, D., Corthésy-Theulaz, I. \& Blum, A. L. (2007). Helicobacter pylori and probiotics. J Nutr 137 (Suppl. 2), 812S-818S.

Magaret, N., Burm, M., Faigel, D., Kelly, C., Peterson, W. \& Fennerty, M. B. (2001). A randomized trial of lansoprazole, amoxycillin, and clarithromycin versus lansoprazole, bismuth, metronidazole and tetracycline in the retreatment of patients failing initial Helicobacter pylori therapy. Dig Dis 19, 174-178.

Malfertheiner, P., Megraud, F., O'Morain, C., Bazzoli, F., El-Omar, E., Graham, D., Hunt, R., Rokkas, T., Vakil, N., Kuipers, E. J. \& The European Helicobacter Study Group (EHSG) (2007). Current 
concepts in the management of Helicobacter pylori infection: the Maastricht III Consensus Report. Gut 56, 772-781.

Markova, B., Proevcska, J., Benisheva, T., Valcheva, J. \& Popova, M. (2005). Antibiotic use and microbial resistance: data from the ESCMID projects EARSS and ESAC for Bulgaria. In Proceedings of the 1st Conference of the Bulgarian Association of Medical Microbiology: Rational Antibiotic Policy, Sofia, Bulgaria.

Megraud, F. (2004). H. pylori antibiotic resistance: prevalence, importance, and advances in testing. Gut 53, 1374-1384.

Megraud, F. \& Lehours, P. (2007). Helicobacter pylori detection and antimicrobial susceptibility testing. Clin Microbiol Rev 20, 280-322.

Mégraud, F., Lehn, N., Lind, T., Bayerdörffer, E., O'Morain, C., Spiller, R., Unge, P., van Zanten, S. V., Wrangstadh, M. \& Burman, C. F. (1999). Antimicrobial susceptibility testing of Helicobacter pylori in a large multicenter trial: the MACH 2 study. Antimicrob Agents Chemother 43, 2747-2752.

Miyachi, H., Miki, I., Aoyama, N., Shirasaka, D., Matsumoto, Y., Toyoda, M., Mitani, T., Morita, Y., Tamura, T. \& other authors (2006). Primary levofloxacin resistance and $g y r A / B$ mutations among Helicobacter pylori in Japan. Helicobacter 11, 243-249.

Morgner, A., Labenz, J. \& Miehlke, S. (2006). Effective regimens for the treatment of Helicobacter pylori infection. Expert Opin Investig Drugs 15, 995-1016.

Muller, A., Coenen, S., Monnet, D. L., Goossens, H. \& ESAC Project Group (2007). European Surveillance of Antimicrobial Consumption (ESAC): outpatient antibiotic use in Europe, 1998-2005. Euro Surveill 12, E071011.1.

NCCLS (2000). Performance Standards for Antimicrobial Susceptibility Testing. Tenth Informational Supplement. Approved standard M100S10 (M7). Wayne, PA: National Committee for Clinical Laboratory Standards.
Nishizawa, T., Suzuki, H., Kurabayashi, K., Masaoka, T., Muraoka, H., Mori, M., Iwasaki, E., Kobayashi, I. \& Hibi, T. (2006). Gatifloxacin resistance and mutations in gyrA after unsuccessful Helicobacter pylori eradication in Japan. Antimicrob Agents Chemother 50, 1538-1540.

Peitz, U., Sulliga, M., Wolle, K., Leodolter, A., Von Arnim, U., Kahl, S., Stolte, M., Borsch, G., Labenz, J. \& Malfertheiner, P. (2002). High rate of post-therapeutic resistance after failure of macrolidenitroimidazole triple therapy to cure Helicobacter pylori infection: impact of two second-line therapies in a randomized study. Aliment Pharmacol Ther 16, 315-324.

Saidijam, M., Benedetti, G., Ren, O., Xu, Z., Hoyle, C. J., Palmer, S. L., Ward, A., Bettaney, K. E., Szakonyi, G. \& other authors (2006). Microbial drug efflux proteins of the major facilitator superfamily. Curr Drug Targets 7, 793-811.

Thyagarajan, S. P., Ray, P., Das, B. K., Ayyagari, A., Khan, A. A., Dharmalingam, S., Rao, U. A., Rajasambandam, P., Ramathilagam, B. \& other authors (2003). Geographical difference in antimicrobial resistance pattern of Helicobacter pylori clinical isolates from Indian patients: multicentric study. J Gastroenterol Hepatol 18, 1373-1378.

Toracchio, S. \& Marzio, L. (2003). Primary and secondary antibiotic resistance of Helicobacter pylori strains isolated in central Italy during the years 1998-2002. Dig Liver Dis 35, 541-545.

Torres, J., Camorlinga-Ponce, M., Pérez-Pérez, G., Madrazo-De la Garza, A., Dehesa, M., González-Valencia, G. \& Muñoz, O. (2001). Increasing multidrug resistance in Helicobacter pylori strains isolated from children and adults in Mexico. J Clin Microbiol 39, 2677-2680.

Tüzün, Y., Bayan, K., Yilmaz, S., Dursun, M. \& Ozekinci, T. (2008). The prevalence of primary and secondary Helicobacter pylori resistance to clarithromycin and probable contributing cofactors: data from southeastern Anatolia. Hepatogastroenterology 55, 289293. 